Journal

International Journal of Public Administration >

Volume 42, 2019 - Issue 1

1750

Views CrossRef citations to date Altmetric

Original Articles

\title{
What Works and Why? Lessons from Public Management Reform in Malaysia
}

Noore Alam Siddiquee $\boldsymbol{\nabla}$, John Antony Xavier \& Mohd Zin Mohamed

Pages 14-27 | Published online: 27 Oct 2017

S6 Download citation

\https://doi.org/10.1080/01900692.2017.1390762

(A) Check for updates

Select Language $\mid \nabla$

Translator disclaimer

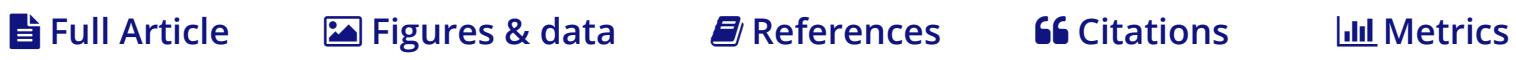

Reprints \& Permissions

Get access

\section{ABSTRACT}

This article examines the Malaysian experience with public management reform to verify arguments about various reform models. Drawing on empirical data, it investigates reforms that have worked and those that have had limited impacts on public service improvements. It identifies critical success factors that determine reform outcomes and concludes that for reforms to succeed a combined top-down and bottom-up approach is crucial. It argues that while diagnostic and problem-oriented reforms have a better chance of being successful, the value of best-practice reforms

should not be discounted. The cumulative impact of such reforms can be significant, as the Malavsian case demonstrates. 
KEYWORDS: Public management reform, best practices, diagnostic model, service delivery, Malaysia

\section{Sample Our}

Economics, Finance, Business \&

Industry journals

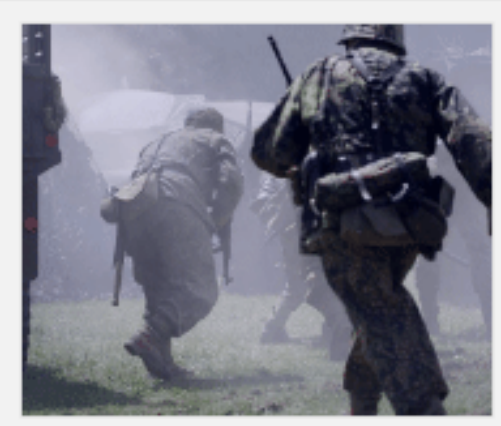

\section{Publlsh open}

access with the
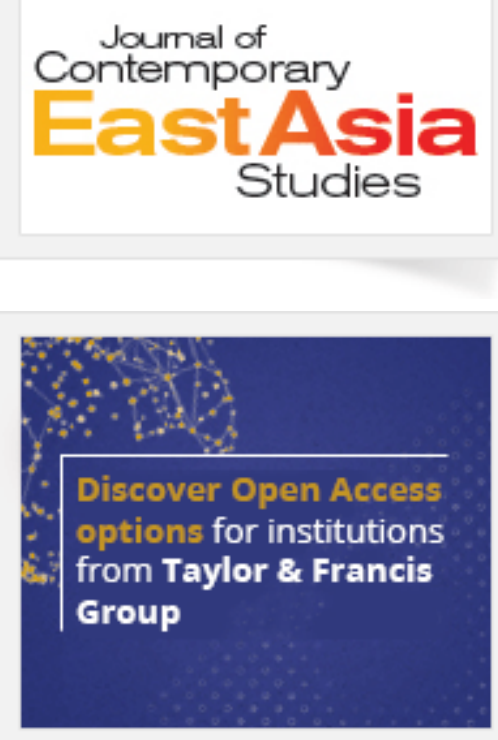

\section{People also read}

\section{Article}

Puhlir Arrnuntahilitv in Malavsia Phallenoses and Critical 